\title{
Effects of Social Activities outside the Home on Life Satisfaction among Elderly People Living Alone
}

\author{
Jun Nakahara ${ }^{1}$ \\ ${ }^{1}$ Graduate School of Human Sciences, Osaka University, Osaka, Japan \\ Correspondence: Graduate School of Human Science, Osaka University, Yamadaoka, Suita 565-0871, Japan. \\ E-mail: j_nakahara@hus.osaka-u.ac.jp
}

Received: January 10, 2013

Accepted: January 23, $2013 \quad$ Online Published: February 21, 2013

doi:10.5539/ijps.v5n1p112

URL: http://dx.doi.org/10.5539/ijps.v5n1p112

\begin{abstract}
This study aims to test the following two hypotheses. First, the life satisfaction of the elderly is not directly affected by their resident status. Second, guided by activity theory and symbolic interaction theory, social activities outside the home (paid work, unpaid work, and hobby/leaning activity) have a greater effect on life satisfaction for elderly people living alone than those living with family members. Participants were 1,774 elderly people who had participated in courses for the elderly to learn various topics, with a final study sample size of 1,539 after flawed survey sheets were removed. T-test findings showed that resident status did not directly influence life satisfaction. A multi-group structural equation model analysis verified that unpaid work has a greater effect on the life satisfaction of the elderly living alone than the one of elderly living alone. These results suggest that unpaid work acts as a buffer effect to decreased life satisfaction.
\end{abstract}

Keywords: elderly living alone, social activities outside the home, activity theory, unpaid work, life satisfaction

\section{Introduction}

\subsection{Problem}

In Japan, there are 3,864,778 elderly people living alone, constituting $15.1 \%$ of all elderly persons (Ministry of Internal Affairs and Communications, 2005). The National Institute of Population and Social Security Research (2008) has predicted an increase in this number in the next 10 years. Many social gerontologists have labeled the period of old age as that of role loss, with the elderly living alone having few family roles that are formed through interaction with family members. Previous studies have found that having various social roles, including family roles, increase subjective well-being (Adelman, 1994; Greenfield \& Marks, 2004; Moen, Dempster-McClain, \& Williams, 1992; Rushing, Litter, \& Burton, 1992; Sugihara, Sugisawa, Shibata, \& Harada, 2008). We predict that elderly people living alone will have lower subjective well-being than elderly people living with their families. However, few studies have proven this hypothesis, and some researchers have argued that resident status was not associated with subjective well-being (Michael, Berkman, Colditz, \& Kawachi, 2001; Sarwari, Fredman, Langenberg, \& Magaziner, 1998). This study focuses on the psychological mechanism involved in these two seemingly contradictory results.

\subsection{Theoretical Background}

In social gerontology, researchers and philosophers have explored the causal relationship between social network or social activity and subjective well-being in terms of activity theory of aging (Lemon, Bengston, \& Peterson, 1972), which was organized in dependence upon symbolic interaction theory (Stryker \& Stantham, 1985; Koyano, 1984). According to activity theory, a social network or social activity brings out roles through a person's interaction with others. When the person internalizes a positional designation, which is gained through interactions in various role relationships, a role-identity is formed, and role-identities collectively form one's self (Burke \& Tulley, 1977). The more positively elderly people form their own role-identity, the better the subjective well-being they have. Previous studies have empirically proven the relationship between various social activities and subjective well-being using activity theory (Larson, 1978; Thoits \& Hewitt, 2001; van Willigen, 2000). Moreover, with family role, past findings have verified the triadic relationship among family interactions, family role-identity (such as grandparent identity or parent identity), and subjective well-being (Nakahara, 2011a; Reitzes \& Mutran, 2006). Thus, from the perspective of activity theory or symbolic interaction theory, social 
network or social activity influences their subjective well-being. Role strain hypothesis is based on too many roles that people use to maintain high subjective well-being. According to this hypothesis, people engaged in different types of roles experience role-conflict, overload, and strain, and consequently their well-being may deteriorate (Goode, 1960). However, as noted earlier, the role strain hypothesis has not been supported, as elderly people in the period of role loss do not have many different roles.

Elderly people living alone have little family roles and positive role-identities, which need to have some interactions with their family members. In order to maintain their subjective well-being at a level of elderly living with family, as previous studies showed (Michael et al, 2001; Sarwari et al., 1998), they may have to acquire social roles and positive role-identities through contact with non-family members outside of their homes. Non-family roles are more important for elderly people living alone than for their peers who live with their family members. We can therefore presume that non-family roles have a greater effect on subjective well-being for elderly people living alone than for their peers living with family (Figure 1).

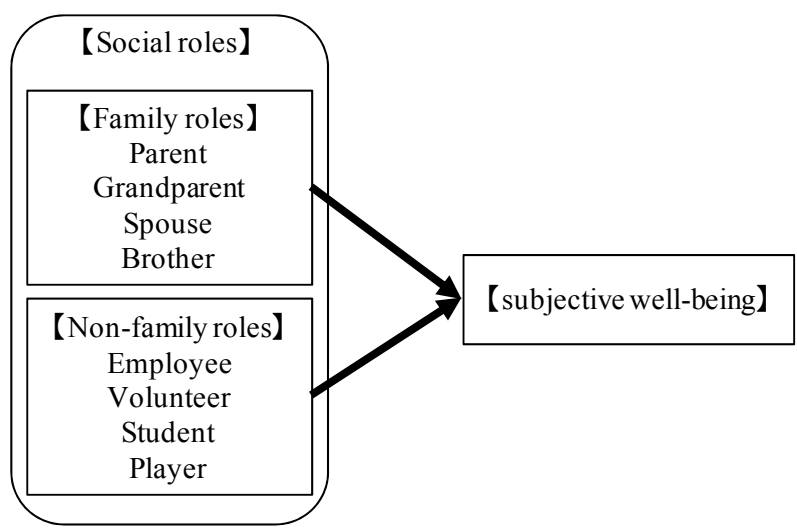

For elderly living with family

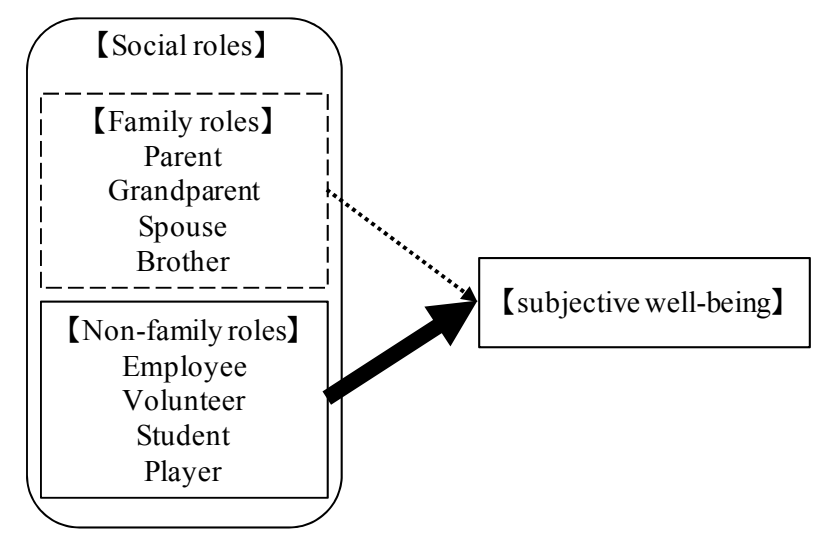

For elderly living alone

Figure 1. Conceptual model of effect on subjective well-being by family and non-family roles

\subsection{Measuring Social Role and Non-Family Role}

There is no standard definition of "society" in social psychology and social gerontology. However, many researchers suggest that the term society assumes an interaction between individuals and one or more people. With this in mind, we define social activity as an activity involving interactions with others. As social activity is similar to social role based on how both of them are measured by quality and quantity of the interaction, previous studies have used social activity as a variable for social role (Grass, Seeman, Herzog, Kahn, \& Berkman, 1995; Greenfield \& Marks, 2004; Nakahara, 2007; Sugihara et al., 2008). Additionally, there are several dimensions to social activity outside the home.

Hashimoto, Aoki, Tamakoshi, Shibasaki, Nagai, Kawakami, Ikari, Ojima, \& Ohno (1997) distributed the social activity of elderly people into paid work, learning activity, engaging in hobbies, and volunteer activity, based on the purpose of each activity. Paid work and volunteer activity are considered productive activity in social gerontology. Klumb and Baltes (1999) have classified productive activity into five categories: domestic activity, errands, gardening, paid work, and helping others. Glass et al. (1995) defined productive activity as housework, paid work, yard work, child care, and volunteering. While many researchers have suggested other definitions or categories, Bass and Caro (2001) have integrated these various definitions as any socially valued activity that produces goods and services, whether paid or not. According to Bass and Caro (2001), Okamoto (2008a) proposed that productive activity involves paid work, unpaid work out of family (e.g., volunteer activity, NPO activity), and unpaid work in the family (e.g., caring, housework) in Japan. This study treats paid work and unpaid work from the family as measurements of a non-family role, because both social activities outside the home are equivalent to a non-family role.

It is valid to deal with these social activities outside the home as social (non-family) roles (Herzog \& House, 1991; Jirovec \& Hyduk, 1998). Past research has not considered hobby/learning activities as a social role variable, and its validity has yet to be proven. However, since hobby/learning activities include interactions with other people, it may be valid to take such activities into consideration as a social role. Thus, for this study, they 
are treated as a measurement of non-family role.

\subsection{Subjective Well-Being and Aging}

Subjective well-being is composed of positive affect, negative affect, and life satisfaction (Diener, 1984; Myers $\&$ Diener, 1995). Positive affect and negative affect are affective components, and life satisfaction is a cognitive component. The results of some aging studies showed that subjective well-being did not decrease with aging, despite various factors related to a decrease of subjective well-being, such as physical, cognitive, and social functions (Löckenhoff \& Carstensen, 2004; Mroczek \& Kolartz, 1998; Nakahara, 2011b). This phenomenon is called "aging paradox" (Nakagawa, 2010) and contradictory results over living alone is reflected as a part of the aging paradox.

In studies on elderly people, life satisfaction has been examined as the more typical parameter to their successful aging than positive and negative affect (Ebner \& Freund, 2006; Neugarten, Havighurst, \& Tobin, 1961). Koyano, Shibata, Haga, and Suyama (1989) developed a scale to measure various components of subjective well-being and came up with the Life Satisfaction Index K or LSIK. Because the LSIK has been widely used in Japanese aging studies (e.g., Nakahara, 2011a; Okamoto, 2008b), for this study, subjective well-being is assessed using LSIK.

\subsection{Purposes and Hypothesis}

This study aims to examine the following two hypotheses.

Hypothesis 1: The life satisfaction of the elderly is not directly affected by their living arrangement.

Hypothesis 2: Social activities outside the home have a greater effect on life satisfaction for elderly people living alone than those living with family members.

\section{Method}

\subsection{Participants}

Recruited participants were 1,774 elderly people who are part of an educational institution for elderly people who learn various topics. To administer the survey, researchers visited every lecture, and distributed and collected census forms in person from July to August 2006. The final study sample size was 1,539 after flawed survey sheets were removed. The mean age of the sample was $66.08(\mathrm{SD}=4.36)$. The gender breakdown was 744 males and 787 females (with seven unknowns).

\subsection{Measures}

The participants responded to four parts of the survey detailing items related to resident status, social activity, subjective well-being, and controlled variables.

\subsubsection{Resident Status}

Participants were asked "Who lives with you?" The categories were: spouse, unmarried children, married children, grandchildren, spouse of sons and daughters, other family members, and living alone. Responses to this item divided participants into two categories: living with family members and living alone.

\subsubsection{Social Activity outside the Home (Non-Family Role)}

Paid work, unpaid work, and hobby/learning activity were measured as indices of social activity, using several items (such as interaction with others) from the Japanese version of the social activity scale for elderly people (Nakahara, 2009; Hashimoto et al., 1997). Paid work included two items about participating in regular employment and the National Silver Human Resources Centers Association. Unpaid work included five items: neighborhood community association, senior citizens' club, volunteer organization, passing down about local tradition, and nonprofit organization. Hobby/learning activities included four items: recreation program, senior college, culture center, and lecture presentation for citizens. Although not all of the concrete activities that occurred in an unpaid organization were productive, when the goal of that organization was productive contributions, participation was considered productive activity. Respondents were asked to report each item on a 3-point scale: 0 . don't participate, 1. participate sometime, and 2. always participate. In the current sample, both unpaid work and the hobby/learning activity scale displayed a certain level of internal consistency $(\alpha=.67$ and .63). Summed scores were created from these items. Scores ranged from 0 to 4 for paid work, 0 to 10 for unpaid work, and 0 to 8 for hobby/learning activity.

\subsubsection{Life Satisfaction (Subjective Well-Being)}

We measured life satisfaction as variables of subjective well-being. Life satisfaction was assessed using the 
LSIK (Life Satisfaction Index K). Previous research has indicated that the LSIK demonstrated high internal consistency and validity as the scale to assess subjective well-being among elderly people (Koyano et al., 1989). The LSIK includes nine items, such as: As I look back on my life, I am fairly well satisfied or When I think back over my life, I didn't get most of the important things I wanted. The life satisfaction score ranged from 0 to 9 .

\subsubsection{Controlled Variables}

The survey items included age, gender, subjective health, subjective economic condition, and education as controlled variables, assessed in the same way as the Nakahara and Fujita (2007) study. Participants rated items utilizing a Likert scale. Subjective health was rated from 1 (extremely poor) to 3 (extremely good), and subjective economic condition was rated from 1 (extremely poor) to 5 (extremely rich). The participants indicated their education status as either 1 ( $<9$ years), 2 (9-12 years), or 3 ( $>12$ years).

\subsection{Statistical Analyses}

Analyses were performed using SPSS 19.0 and Amos 19.0. Hypothesis 1 was verified using t-test. In order to determine the validity of hypothesis 2 , a multi-group structural equation model analysis was conducted. This analytical model was a regression model on life satisfaction by each social activity with controlled variables for the elderly separated by their resident status (living with family or living alone). The most basic model was one whose equipollent constraint was imposed on all paths from the independent variables. Invariance testing compared a highly constrained model (model 1) with models that systematically relaxed parameters between groups. This approach allowed us to test whether each social activity for the elderly living alone had a greater effect on life satisfaction than that for the elderly living with families.

\section{Results}

There were 720 male (54\%) and 613 female (46\%) elderly people living with families, and 23 male (12\%) and 169 female (88\%) elderly people living alone. A chi-square analysis on gender found a significant difference between the elderly living with family and those living alone: $\mathrm{C}^{2}(1)=118.69, \mathrm{p}<.01$. Although most of the elderly living alone in this study were female, this analytical sample reflects the current Japanese population structure, as there are more female elderly people living alone (73\%) (Ministry of Internal Affairs and Communications, 2005). Table 1 presents descriptive statistics for the analytical sample. The t-test result suggests that the elderly living alone were older and in a worse economic condition than the elderly living with families. There were no differences in resident status for each social activity or life satisfaction. In particular, there was no difference in life satisfaction between resident status; this confirms the validity of hypothesis 1 as drawn from previous researches.

Table 1. Descriptive statistics of the elderly living with families and the elderly living alone

\begin{tabular}{|c|c|c|c|c|c|}
\hline & \multicolumn{2}{|c|}{$\begin{array}{l}\text { elderly living } \\
\text { with family }\end{array}$} & \multicolumn{2}{|c|}{$\begin{array}{l}\text { elderly living } \\
\text { alone }\end{array}$} & \multirow{2}{*}{$\frac{\mathrm{t} \text {-test }}{\mathrm{p}}$} \\
\hline & Mean & (SD) & Mean & (SD) & \\
\hline age & 65.91 & $(4.24)$ & 67.25 & $(4.96)$ & $\mathrm{p}<.01$ \\
\hline subjective economic condition & 3.06 & $(0.73)$ & 2.94 & $(0.82)$ & $\mathrm{p}<.05$ \\
\hline subjective health & 1.47 & $(0.52)$ & 1.52 & $(0.53)$ & n.s. \\
\hline education & 1.44 & $(0.53)$ & 1.38 & $(0.51)$ & n.s. \\
\hline paid work & 0.49 & $(0.82)$ & 0.55 & $(0.91)$ & n.s. \\
\hline unpaid work & 2.48 & $(2.11)$ & 2.74 & $(2.19)$ & n.s. \\
\hline hobby/learning activity & 4.17 & $(1.75)$ & 4.42 & $(1.96)$ & n.s. \\
\hline life satisfaction & 5.51 & $(1.96)$ & 5.26 & $(2.02)$ & n.s. \\
\hline
\end{tabular}

Bivariate associations among the variables were estimated using Pearson product-moment correlations. Table 2 shows the correlation coefficients for all variables. Above the diagonal line are the correlations for the elderly living with family members, and below the line for the elderly living alone. Results indicate that there are 
differences of association between each social activity and life satisfaction. Paid work was not significantly associated with life satisfaction among all elderly people $(r=.03$ or $.09, p>.05)$. However, both unpaid work and hobby/learning activity were significantly associated with life satisfaction for all the elderly $(\mathrm{r}=.11-.29, \mathrm{p}$ $<.01)$. Additionally, the relationship between age and life satisfaction for the elderly living with families $(\mathrm{r}=$ $-.12, \mathrm{p}<.01)$ differed from the elderly living alone $(\mathrm{r}=.16, \mathrm{p}<.05)$. This finding indicates that age had a reverse-directed effect by resident status.

Table 2. Bivariate associations for all variables

\begin{tabular}{lccccccccc}
\hline & 1 & 2 & 3 & 4 & 5 & 6 & 7 & 8 & 9 \\
\hline 1. gender(1=female) & - & $-.21^{* *}$ & $.08^{* *}$ & $-.06^{*}$ & $-.26^{* *}$ & $-.08^{* *}$ & $.10^{* *}$ & $.12^{* *}$ & $.10^{* *}$ \\
2. age & $-.16^{* *}$ & - & -.03 & .03 & -.01 & .03 & .05 & $-.07^{*}$ & $-.12^{* *}$ \\
3. subjective economic condition & .11 & .09 & - & $-.14^{* *}$ & .02 & -.01 & .03 & $.11^{* *}$ & $.29^{* *}$ \\
4. subjective health & -.05 & .05 & .01 & - & -.04 & -.02 & -.05 & $-.14^{* *}$ & $-.26^{* *}$ \\
5. education & $-.23^{* *}$ & .05 & .13 & .09 & - & .02 & -.01 & $.06^{*}$ & -.01 \\
6. paid work & .03 & -.04 & -.01 & $-.17^{*}$ & -.12 & - & $.19^{* *}$ & $.08^{* *}$ & .03 \\
7. unpaid work & .04 & .06 & .10 & .13 & .15 & $.16^{*}$ & - & $.40^{* *}$ & $.11^{* *}$ \\
8. hobby/learning activity & .15 & -.14 & .14 & -.03 & -.05 & $.29^{* *}$ & $.34^{* *}$ & - & $.21^{* *}$ \\
9. life satisfaction & .06 & $.16^{*}$ & $.29^{* *}$ & $-.22^{* *}$ & $.17^{*}$ & .09 & $.29^{* *}$ & $.24^{* *}$ & - \\
\hline
\end{tabular}

Note. Correlations above the diagonal line refer to the elderly living with families while those below the diagonal line refer to the elderly living alone. ${ }^{* *} \mathrm{p}<.01,{ }^{*} \mathrm{p}<.05$

Table 3 shows the multi-group structural equation model analysis. We analyzed the following models: model 1 with all paths equally estimated between groups; model 2 with only the path from age to life satisfaction separated; model 3 with only the path from paid work to life satisfaction separated; model 4 with only the path from unpaid work to life satisfaction separated; and model 5 with only the path from hobby/learning activity to life satisfaction separated. The analysis indicated that the fit indexes for models 2 and 4 were better than model 1 . When we estimated the effect of age or unpaid work separately between the elderly living with families and the elderly living alone, every fit index improved. We next analyzed a sixth model, with the paths from both age and unpaid work to life satisfaction freely estimated between groups. Model 6 provided the best fit among all the models $(\mathrm{CMIN} / \mathrm{DF}=1.219, \mathrm{AIC}=211.313, \mathrm{CFI}=.998, \mathrm{RMSEA}=.012)$.

Table 3. Comparison of fit indexes among all models

\begin{tabular}{llcccc}
\hline & & CMIN/DF & AIC & CFI & RMSEA \\
\hline model 1 & equal all paths & 2.963 & 223.706 & .980 & .036 \\
model 2 & free only the path from age & 1.616 & 213.315 & .994 & .020 \\
model 3 & free only the path from paid work & 3.374 & 225.621 & .979 & .039 \\
model 4 & free only the path from unpaid work & 2.785 & 221.494 & .984 & .034 \\
model 5 & $\begin{array}{l}\text { free only the path from hobby/learning activity } \\
\text { model } 6\end{array}$ & 3.377 & 225.641 & .979 & .039 \\
& $\begin{array}{l}\text { free the each path from age and unpaid work } \\
\text { (all other paths equal) }\end{array}$ & 1.219 & 211.313 & .998 & .012 \\
\hline
\end{tabular}

Table 4 presents the regression coefficient on life satisfaction for each group (model 6). For both groups, increased hobby/learning activity was significantly associated with high life satisfaction $(B=0.15, p<.01)$, but 
not paid work. On the other hand, the effects of age and unpaid work appeared to be different between the two groups. For the elderly living with families, age negatively influenced life satisfaction $(B=-0.04, p<.01)$, but the effect was opposite for the elderly living alone $(B=0.07, p<.01)$. For the elderly living alone, increased unpaid work was significantly associated with high life satisfaction $(B=0.19, \mathrm{p}<.01)$, but there was no association for the elderly living with families. Additionally, a t-test analysis to examine the differences in regression coefficient between groups found that the influence of age or unpaid work on life satisfaction was significantly different $\left(\mathrm{t}_{\text {age }}=3.45, \mathrm{p}<.01, \mathrm{t}_{\text {unpaid work }}=2.10, \mathrm{p}<.05\right)$.

Table 4. Regression coefficients on life satisfaction

\begin{tabular}{lcccccccc}
\hline & \multicolumn{8}{c}{ model 6} \\
\cline { 2 - 4 } & \multicolumn{2}{c}{ elderly living with family } & & \multicolumn{3}{c}{ elderly living alone } \\
& $\mathrm{B}$ & $\beta$ & $\mathrm{SE}$ & & $\mathrm{B}$ & $\beta$ & $\mathrm{SE}$ \\
\hline age & $-0.04^{* *}$ & -.09 & .01 & & $0.07^{*}$ & .16 & .03 \\
non family role & & & & & & & \\
$\quad$ paid work & 0.01 & .01 & .06 & & $=0.01$ & -.01 & $=.06$ \\
$\quad$ unpaid work & 0.04 & .04 & .03 & & $0.19^{* *}$ & -.21 & .07 \\
hobby/learning activity & $0.15^{* *}$ & .13 & .03 & & $=0.15^{* *}$ & -.15 & $=.03$ \\
\hline R square & $.17^{* *}$ & & & & $.23^{* *}$ & & \\
$\mathrm{n}$ & 1334 & & & & 192 & & \\
\hline
\end{tabular}

Note. Gender, subjective economic condition, subjective health, and education are controlled as exogenous variable. ${ }^{* *} \mathrm{p}<.01,{ }^{*} \mathrm{p}<.05$

\section{Discussion}

The purposes of this study were to test two hypotheses. As predicted in hypothesis 1, life satisfaction among the elderly was not directly affected by their living arrangement (Table 1). This result is consistent with the findings of Michael et al. (2001) and Sarwari et al. (1998) that resident status is not associated with subjective well-being, and provides further empirical support for the assertion that resident status of living alone doesn't directly influences negative life satisfaction. This finding implies that there are protective factors to decreasing life satisfaction by living on one's own.

We considered non-family role as one of the protective factors based on the activity theory and symbolic interaction theory, and tested hypothesis 2 that social activities outside the home have a greater effect on life satisfaction for elderly people living alone than them living with family members. The multi-group structural equation model analysis suggests that unpaid work is the only protective factor. In other words, unpaid work has the same meaning as a non-family role, and these results indicate the buffering effect provided to decrease life satisfaction due to a lack of family roles. When social gerontologists treated social activity as a social role in past studies, the typical example used was unpaid work, such as volunteering (Greenfield \& Marks, 2004; Nakahara, 2007), wherein the volunteers indentified their roles themselves (Herzog \& House, 1991; Jirovec \& Hyduk, 1998). This suggests that we can discuss the effect on subjective well-being through social activity as a non-family role, but only if unpaid work was treated as a social activity. It is important that the protective effect of unpaid work as a non-family role is verified empirically in this study.

In contrast, paid work and hobby/learning activity did not bring about the protective effects as postulated in hypothesis 2 . However, hobby/leaning activity positively influenced life satisfaction regardless of resident status. This finding suggests that, other than activity theory (such as social support or affiliation motive), social gerontologists need to find an alternate explanation to the psychological mechanism that hobby/learning activity influences subjective well-being. At the very least, our findings indicate that the complementary relationship between family role and hobby/learning activity on subjective well-being, guided by activity theory, could not be found.

Paid work influences life satisfaction in relation to resident status. Although the larger social network or the greater social role brings about better subjective well-being in theory, our result suggests that paid work involves various individual situations. Nakazato et al. (2000) suggested the necessity of considering the reasons for 
working at an individual level. Paid workers in poor living condition have to earn their money independently of their will; thus, their paid work does not positively influence subjective well-being. In that sense, paid work might be qualitatively different from unpaid work and hobby/learning activity, because the latter are social activities that the elderly participate in of their own free will. We should not try to organize the effect of paid work, but consider each individual case by judging their effect on subjective well-being.

There are two ways in which the results of this study contribute to the literature of activity theory. First, this study advances our knowledge of the relationship between social activity outside the home and subjective well-being as a protective effect of unpaid work against the lack of family roles. Second, not every kind of social activity is explained by the view of activity theory for the effect on subjective well-being. Additionally, our results have a practical implication for the elderly Japanese living alone: the importance of non-family role heightens particularly in unpaid work, should they live alone through bereavement or estrangement. For successful aging, it may be important for the elderly to participate in voluntary work before they end up living alone.

\section{Limitations}

Some limitations of the present research should be noted. First, the effect of hobby/learning activity should be interpreted carefully because all the respondents were recruited from a specific senior college. As such, we might not be able to detect its effect exactly. Second, reflecting on the current Japanese population structure, most of the elderly living alone were female. Although the present data is considered valid for all elderly people living alone, we cannot eliminate the possibility that the results may apply only to older women living alone. More data from older men living alone need to be collected and analyzed. Third, we were unable to prevent the error contained in the measurement scales for non-family role (social activity). In other words, we had to include other components, such as amount of support or physical activity, in the items for non-family role. This reflects the difficulty that most past studies have tried to resolve regarding social activity. Social gerontologist and psychologists will need to better define concepts and measurements involving social role and social activity.

\section{Acknowledgements}

The auther would like to thank Prof. Ayako Fujita and the group members of aging study in Osaka University, for their assistance on the dissertation research behind this study.

\section{References}

Adelman, P. K. (1994). Multiple roles and psychological well-being in a national sample of older adults. Journal of Gerontology: Social Sciences, 49B, S277-S285. http://dx.doi.org/10.1093/geronj/49.6.S277

Bass, S. A., \& Caro, F. G. (2001). Productive aging: A conceptual framework. In N. Morrow-Howell, J. Hinterlong, \& M. Sherradan (Eds.), Productive aging: Concepts and challenges (pp. 37-80). Baltimore: John Hopkins Univesity Press.

Burke, P. J., \& Tully, J. (1977). The measurement of role/identity. Social Forces, 55, 881-897.

Diener, E. (1984). Subjective well-being. Psychological Bulletin, 95, 542-575. http://dx.doi.org/10.1037/0033-2909.95.3.542

Ebner, N. C., \& Freund, A. M. (2006). Personality theories of successful aging. In J. A. Blackburm, \& C. N. Dulmus (Eds.), Handbook of gerontology; Evidence-based approaches to theory, practice, and policy (pp. 87-116). New Jersey: Hoboken.

Glass, T. A., Seeman, T. E., Herzog, A. R., Kahn, R., \& Berkman, L. F. (1995). Change in productive activity in late adulthood: MacArthur studies of successful aging. Journal of Gerontology: Social Sciences, 50B, S65-S76. http://dx.doi.org/10.1093/geronb/50B.2.S65

Goode, W. J. (1960). A theory of role strain. American Sociological Review, 25, 483-496.

Greenfield, E. A., \& Marks, N. F. (2004). Formal volunteering as a prospective factor for older adults' psychological well-being. Journal of Gerontology: Social Sciences, 59B, S258-S264. http://dx.doi.org/10.1093/geronb/59.5.S258

Hashimoto, S., Aoki, R., Tamakoshi, A., Shibasaki, S., Nagai, M., Kawakami, N., Ikari, A., Ojima, T., \& Ohno, Y. (1997). Development index of social activities for the elderly. Japanese Journal of Public Health, 44, 760-768.

Herzog, A. R., \& House, J. S. (1991). Productive activities and aging well. Generations, 15, 49-54.

Jirovec, R. L., \& Hyduk, C. A. (1998). Type of volunteer experience and health among plder adult volunteers. 
Journal of Gerontological Social Work, 30, 29-42. http://dx.doi.org/10.1300/J083v30n03_04

Klumb, P. L., \& Baltes, M. M. (1999). Time use of old and very old Berliners: Productive and consumptive activities as functions of resources. Journal of Gerontology: Social Sciences, 54B, S271-S278. http://dx.doi.org/10.1093/geronb/54B.5.S271

Koyano, W. (1984). Symbolic interactionism, structural functionalism and the theories of successful aging (1): Activity theory of aging. Teologia-diakonia, 17, 103-115.

Koyano, K., Shibata, H., Haga, H., \& Suyama, Y. (1989). Structure of a life satisfaction index: Multidimensionality of subjective well-being and its measurement. Japanese Journal of Gerontology, 11, 99-125.

Larson, R. (1978). Thirty years of research on the subjective well-being of older Americans. Journal of Gerontology, 30, 85-89. http://dx.doi.org/10.1093/geronj/33.1.109

Lemon, B. W., Bengston, V. L., \& Peterson, J. A. (1972). An exploration of the activity theory of aging. Journal of Gerontology, 27, 511-523. http://dx.doi.org/10.1093/geronj/27.4.511

Löckenhoff, C. E., \& Carstensen, L. L. (2004). Socioemotional selectivity theory, aging, and health: The increasing delicate balance between regulating emotions and making tough choice. Journal of Personality, 72, 1395-1424. http://dx.doi.org/10.1111/j.1467-6494.2004.00301.x

Moen, P., Dempster-McClain, D., \& Williams, R. (1992). Successful aging: A life-cource perspective on women's multiple roles and health. American Journal of Sociology, 97, 1612-1638.

Michael, Y. L., Berkman, L. F., Colditz, G. A., \& Kawachi, I. (2001). Living arrangement, social integration, and change in functional health status. American Jounrnal of Epidemiology, 153, 123-131. http://dx.doi.org/10.1093/aje/153.2.123

Ministry of Internal Affairs and Communications. (2005). Population Census. Statistics Bureau, Director-general for Policy Planning (Statistical Standards) and Statistical Research and Training Institute, Retrieved from http://www.stat.go.jp/english/data/kokusei/index.htm

Mroczek, D. K., \& Kolarz, C. M. (1998). The effects of age on positive and negative affect: A developmental perspective on happiness. Journal of Personality and Social Psychology, 75, 1333-1349. http://dx.doi.org/10.1037/0022-3514.75.5.1333

Myers, D. G., \& Diener, E. (1995). Who is happy? Psychological Science, 6, 10-19. http://dx.doi.org/10.1111/j.1467-9280.1995.tb00298.x

Nakagawa, T. (2010). Theory of psychological adaptation in old age. Bulletin of Behavioral Sciences of Life, Aging, Sickness and Death, 15, 31-39.

Nakahara, J. (2007). The buffer-effect of volunteer activities onto the poor psychological well-being among middle-aged and elderly persons with lacking roles. Journal of Care and Behavioral Sciences for the Elderly, 13, 15-22.

Nakahara, J. (2009). Effects of role loss and productive role on self-esteem of the elderly in Japan and America. In T. Kikkawa (Ed.), The bulletin report of scientific research fund in 2006-2009 (pp. 211-219). School of human sciences Osaka University.

Nakahara, J. (2011a). The relationship between grandparent role and subjective well-being of young-olds. Japanese Journal of Psychology, 82, 158-166.

Nakahara, J. (2011b). Deliberation on factor structure on affective well-being scale and the development of its short version. Japanese Journal of Gerontology, 32, 434-442.

Nakahara, J., \& Fujita, A. (2007). The relation between middle-aged people's current way of life and their expected way of life in their old age. Japanese Journal of Gerontology, 29, 30-36.

Nakazato, K., Shimonaka, Y., Kawaai, C., Ishihara, O., Gondo, Y., Inagaki, H. (2000). Differential adaptation process to complete retirement from job and unemployment among middle aged and the elderly Japanese. Japanese Journal of Gerontology, 22, 37-45.

National Institute of Population and Social Security Research. (2008). Population Statistics of Japan 2008. Retrieved from http://www.ipss.go.jp/p-info/e/psj2008/PSJ2008.html

Neugarten, B. L., Havighutst, R. J., \& Tobin, S. S. (1961). The measurement of life satisfaction. Journal of Gerontology, 16, 134-143. http://dx.doi.org/ 10.1093/geronj/16.2.134 
Okamoto, H. (2008a). Factors associated with productive activities among the elderly; Paid work and unpaid work at home and outside the home among men and women. Japanese Journal of Gerontology, 29, 526-538.

Okamoto, H. (2008b). Effects of social activities on life satisfaction among the elderly: Four aspects in men and women. Japanese Journal of Public Health, 55, 388-395.

Reitzes, D. C., \& Mutran, E. J. (2006). Self and health: Factor that encourage self-esteem and functional health. Journal of Gerontology: Social Sciences, 61B, S44-S51. http://dx.doi.org/10.1093/geronb/61.1.S44

Rushing, B., Ritter, C., \& Burton, R. P. D. (1992). Race differences in the effects of multiple roles on health: Longitudinal evidence from a national sample of older men. Journal of Health and Social Behavior, 33, 126-139. http://dx.doi.org/10.2307/2137251

Sarwari, A. R., Fredman, L., Langenberg, P., \& Magaziner, J. (1998). Prospective study on the relation between living arrangement and change in functional health status of elderly women. American Journal of Epidemiology, 147, 370-378.

Stryker, S., \& Stantham, A. (1985). Symbolic Interaction and Role Theory. In L. Gardner, \& E. Aronson. (Eds.), Handbook of Social Psychology (pp. 311-378). New York: Random House..

Sugihara, Y., Sugisawa, H., Shibata, H., \& Harada, K. (2008). Productive Roles, gender, and depressive symptoms: Evidence from a national longitudinal study of late-middle-aged Japanese. Journal of Gerontology: Psychological Sciences, 63B, P227-P234. http://dx.doi.org/10.1093/geronb/63.4.P227

Thoits, P. A., \& Hewitt, L. N. (2001). Volunteer work and well-being. Journal of Health and Social Behavior, 42, 115-131.

van Willigen, M. (2000). Differential benefits of volunteering across the life course. Journal of Gerontology: Social Sciences, 55B, S308-S318. http://dx.doi.org/10.1093/geronb/55.5.S308 